(1)

CrossMark

\title{
The scale of the problem of obstructive lung disease in Africa becomes clearer, but where are the solutions?
}

\author{
Rupert Jones
}

Affiliation: Peninsula School of Medicine, Plymouth University, Plymouth, UK.

Correspondence: Rupert Jones, Peninsula School of Medicine, Plymouth University, 1 Davy Rd, Plymouth, PL6 8BU, UK. E-mail: rupert.jonesवplymouth.ac.uk

@ERSpublications

COPD is a common and important disease in rural Tanzania, and may relate to biomass smoke exposure http://ow.ly/MCv030hKe86

Cite this article as: Jones R. The scale of the problem of obstructive lung disease in Africa becomes clearer, but where are the solutions? Eur Respir J 2018; 51: 1702562 [https://doi.org/10.1183/13993003.02562-2017].

If you breathe in toxic air, lung damage will result. In much of sub-Saharan Africa as well as Asia, massive exposures to a range of toxic air from household air pollution, ambient air pollution and occupational exposures occur with consequent rising morbidity and mortality. The headline statistics are extraordinary: globally, in 2015, 2.8 people million died from household air pollution and 4.2 million people from ambient air pollution [1]. Chronic obstructive pulmonary disease (COPD) is now the third leading cause of death, with 3.2 million deaths worldwide and the same number dying from lower respiratory tract infections [2]. The prevalence of COPD is rising inexorably in Africa [3] but do we really understand the roots of rising tide of COPD and its relationship to air pollution?

In a carefully conducted survey in rural Tanzania, the prevalence of spirometrically defined COPD was $17 \%$ (22\% in men, $13 \%$ in women) [4]. This figure was strikingly similar to a similar survey in neighbouring Uganda, which found a prevalence of $16 \%$ [5]. This study is welcome because previous estimates in Africa are variable and lack harmonisation of definitions [3, 6].

Spirometrically defined COPD is not a disease but a physiological marker; the diagnosis of COPD as per the Global Initiative for Chronic Obstructive Lung Disease (GOLD) includes clinical features and symptoms as key components [7]. In the study in Tanzania, cough and sputum were equally prevalent in COPD and non-COPD groups, but markers of breathlessness were much higher in the COPD group. While those with spirometrically diagnosed COPD were largely symptomatic, so too were many with normal spirometry; for example, $44 \%$ had cough and sputum, perhaps from household air pollution. Thus, the danger of detecting abnormal physiology and creating a disease that does not exist was small, but not without implications. Asymptomatic airflow obstruction in GOLD stage 1 is not associated with progressive disease [8]. No one knows if people in Africa with airflow obstruction detected in a survey have a progressive and serious disorder, and longitudinal studies are urgently needed.

Received: Dec 102017 | Accepted after revision: Dec 182017

Conflict of interest: R. Jones has received grants, personal fees and nonfinancial support from AstraZeneca, personal fees from Boehringer Ingelheim, Chiesi and Pfizer, personal fees and nonfinancial support from GSK, grants and personal fees from Novartis, and nonfinancial support from Nutricia, outside the submitted work.

Support statement: R. Jones is supported by the PENCLAHRC research network. Funding information for this article has been deposited with the Crossref Funder Registry.

Copyright CERS 2018 
FIGURE 1 Women and children are exposed to high levels of biomass smoke.

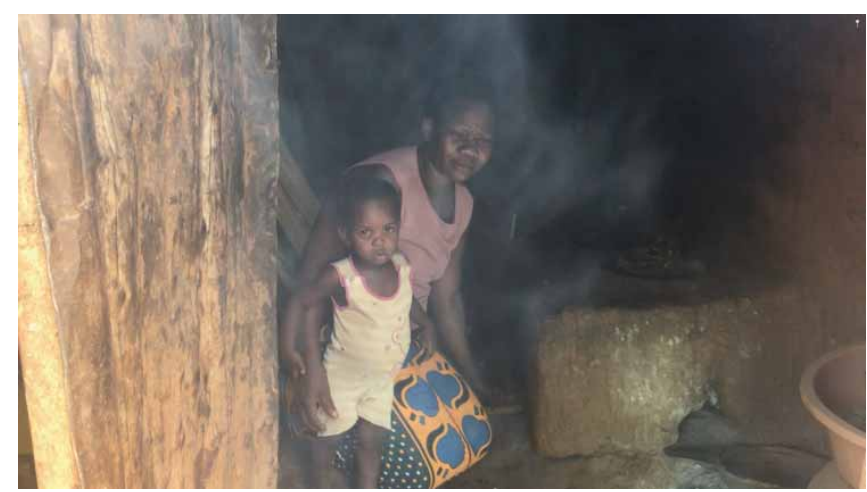

Accepting the limits of the methods of detecting cases, why are relatively young people developing COPD? Only $5 \%$ of the surveyed population were current smokers; in contrast, $99.7 \%$ of participants were exposed to biomass smoke. The answer may be that biomass smoke causes impaired lung growth as well as adult lung damage. Lung growth as a determinant of adult lung disease was considered in a study in three large cohorts from the USA and Denmark: of adults diagnosed with COPD in their 60s, half reached this point from accelerated lung decline and half from impaired lung growth [9]. Surely, the major exposures at high intensity and for long duration in children raised in Africa are likely to make a major contribution to impaired lung growth and reduced adult lung function (figures 1 and 2). Babies are kept with their mothers during the long hours of cooking African staple diets. Poor lung growth may also be exacerbated by poor nutrition in utero and in early years [10] and thus reduce adult lung function.

There are also complex interactions at work in the genesis of the lung damage described as COPD in Africa. Chronic damage may arise from respiratory infections such as tuberculosis and from asthma, and biomass smoke exposure predisposes to both. Damaged lungs are more prone to infections, so a vicious cycle arises. Susceptibility to infection and inflammatory lung disease may also be affected by poor nutrition, reduced immunity and poverty [11]. Biomass fuels are used by the poorest people and epidemiological studies showing an association between biomass smoke and COPD may be confounded by poverty [12]. Globally poverty is important in COPD, as COPD mortality rates relate to poverty; whereas COPD prevalence rates are more closely related to tobacco smoking [13].

While defining the problem of COPD and its risk factors is critical, what Africa needs is not more problems: the search now should turn to solutions [14]. Is biomass smoke a preventable cause of COPD? While neither the Ugandan nor the Tanzanian study was powered to detect biomass smoke as a cause of COPD, the World Health Organization unequivocally sates that "Over one-third of premature deaths from chronic obstructive pulmonary disease (COPD) in adults in low- and middle-income countries are due to exposure to household air pollution" [15]. These estimates are important but are based on some very broad assumptions. The underpinning epidemiological studies, in fact, provide mixed results [13, 16, 17]. Many studies contrast current exposures with obstructive lung disease. However, this is not entirely logical, as current tobacco exposure is poorly related to COPD; what matters is lifelong dose calculated from duration and intensity of exposure, analogous to pack-years. Epidemiological studies need to be supplemented by intervention studies and here, evidence is lacking [18].

Intervention studies reducing household air pollution tend to focus on a single control facet such as installing chimneys in houses in Guatemala [19] or energy-efficient cooking stoves in the Cooking and

FIGURE 2 Children are at risk of developing lung disease.

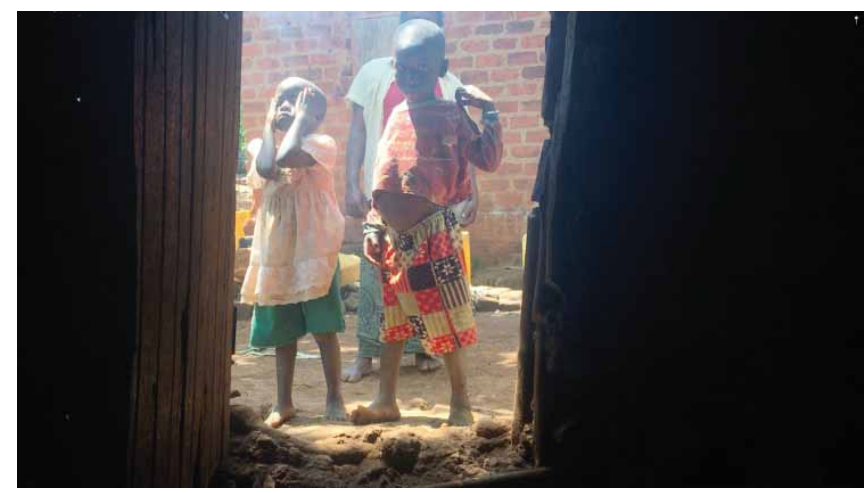


Pneumonia Study (CAPS) in Malawi [20]. These studies used childhood pneumonia as the primary end-point; data on COPD are a long way off. The Guatemala study showed that reducing household air pollution was associated with a reduction in symptoms such as cough and sore eyes, but not with a significant reduction in childhood pneumonia [19]. In CAPS, a significant reduction in childhood pneumonia was not attained, probably because the intervention did not effectively reduce biomass smoke exposure [20].

A pragmatic, community-wide approach was adopted in a lung health awareness-raising programme in Uganda [21]. The project involved an education and awareness-raising approach through the local health service and local government, in villages, and on mass media. To protect the most vulnerable, emphasis was placed on protecting children by working with all grades of health professionals, including midwives, to keep unborn babies and infants away from smoke. Potential benefits of reducing smoke exposure include reducing obstetric complications, neonatal deaths and respiratory infections in infants [22, 23]. In the longer term, early-life exposure to household air pollution may reduce lung function in adults [24] and increase the chance of COPD as an adult [23]. While such pragmatic interventions are needed, their value is hard to estimate in controlled trials for obvious reasons of time, money and ethics.

Even as research grapples with the problems of indoor air pollution, the complexity of outdoor air born lung toxicity is growing. Household air pollution now includes in increasing array of chemicals from burning plastic and rubbish, as well as bacterial endotoxins and a huge range of chemicals from plant materials [25]. The Lancet Commission on pollution and health found that household air pollution is now overshadowed by the rise of ambient air pollution and the range of different toxins in air pollution are vast [26]. Thus, the complexity of chemical insults to the lungs is becoming hard to fathom.

Thanks to papers such as by MAGITTA et al. [4] in this journal, the scale and long-term implications of COPD in Africa are beginning to be seen more clearly, but there are so many questions still remaining about the causes of COPD and how best to address it. Research is needed on a scale which matches the problem, and that is not forthcoming [27]. COPD is a silent but not acceptable epidemic. It is time to clear the air.

\section{References}

1 GBD 2015 Risk Factors Collaborators. Global, regional, and national comparative risk assessment of 79 behavioural, environmental and occupational, and metabolic risks or clusters of risks, 1990-2015: a systematic analysis for the Global Burden of Disease Study 2015. Lancet 2016; 388: 1659-1724.

2 World Health Organization. The top 10 causes of death. Geneva, WHO, 2014.

3 Adeloye D, Basquill C, Papana A, et al. An estimate of the prevalence of COPD in Africa: a systematic analysis. COPD 2015; 12: 71-81.

4 Magitta NF, Walker RW, Apte KK, et al. Prevalence, risk factors and clinical correlates of COPD in a rural setting in Tanzania. Eur Respir J 2018; 51: 1700182.

5 van Gemert F, Kirenga B, Chavannes N, et al. Prevalence of chronic obstructive pulmonary disease and associated risk factors in Uganda (FRESH AIR Uganda): a prospective cross-sectional observational study. Lancet Glob Health 2015; 3: e44-e51.

6 Soriano JB, Abajobir AA, Abate KH, et al. Global, regional, and national deaths, prevalence, disability-adjusted life years, and years lived with disability for chronic obstructive pulmonary disease and asthma, 1990-2015: a systematic analysis for the Global Burden of Disease Study 2015. Lancet Respir Med 5: 691-706.

7 Vogelmeier CF, Criner GJ, Martinez FJ, et al. Global Strategy for the Diagnosis, Management, and Prevention of Chronic Obstructive Lung Disease 2017 Report: GOLD Executive Summary. Eur Respir J 2017; 49: 1700214.

8 Bridevaux PO, Gerbase MW, Probst-Hensch NM, et al. Long-term decline in lung function, utilisation of care and quality of life in modified GOLD stage 1 COPD. Thorax 2008; 63: 768-774.

9 Lange P, Celli B, Agustí A, et al. Lung-function trajectories leading to chronic obstructive pulmonary disease. N Engl J Med 2015; 373: 111-122.

10 Hancox RJ, Poulton R, Greene JM, et al. Associations between birth weight, early childhood weight gain and adult lung function. Thorax 2009; 64: 228-232.

11 van Zyl Smit RN, Pai M, Yew WW, et al. Global lung health: the colliding epidemics of tuberculosis, tobacco smoking, HIV and COPD. Eur Respir J 2010; 35: 27-33.

12 Townend J, Minelli C, Mortimer K, et al. The association between chronic airflow obstruction and poverty in 12 sites of the multinational BOLD study. Eur Respir J 2017; 49: 1601880.

13 Burney P, Jarvis D, Perez-Padilla R. The global burden of chronic respiratory disease in adults. Int J Tuberc Lung Dis 2015; 19: 10-20.

14 Gordon SB, Bruce NG, Grigg J, et al. Respiratory risks from household air pollution in low and middle income countries. Lancet Respir Med 2014; 2: 823-860.

15 World Health Organization. Household air pollution and health. Geneva, WHO, 2016.

16 Assad NA, Kapoor V, Sood A. Biomass smoke exposure and chronic lung disease. Curr Opin Pulm Med 2016; 22 : $150-157$.

17 Schikowski T, Mills IC, Anderson HR, et al. Ambient air pollution: a cause of COPD? Eur Respir J 2014; 43: 250-263.

18 Quansah R, Semple S, Ochieng CA, et al. Effectiveness of interventions to reduce household air pollution and/or improve health in homes using solid fuel in low-and-middle income countries: a systematic review and meta-analysis. Environ Int 2017; 103: 73-90. 
19 Smith KR, McCracken JP, Weber MW, et al. Effect of reduction in household air pollution on childhood pneumonia in Guatemala (RESPIRE): a randomised controlled trial. Lancet 378: 1717-1726.

20 Mortimer K, Ndamala CB, Naunje AW, et al. A cleaner burning biomass-fuelled cookstove intervention to prevent pneumonia in children under 5 years old in rural Malawi (the Cooking and Pneumonia Study): a cluster randomised controlled trial. Lancet 2017; 389: 167-175.

21 IPCRG. Education about Tobacco Dependence - IPCRG and Global Bridges Uganda. www.theipcrg.org/display/ TeachColleagues/Education+about+Tobacco+Dependence+-+IPCRG+and+Global+Bridges+Uganda

22 Amegah AK, Quansah R, Jaakkola JJ. Household air pollution from solid fuel use and risk of adverse pregnancy outcomes: a systematic review and meta-analysis of the empirical evidence. PLoS One 2014; 9: e113920.

23 Fullerton DG, Bruce N, Gordon SB. Indoor air pollution from biomass fuel smoke is a major health concern in the developing world. Trans R Soc Trop Med Hyg 2008; 102: 843-851.

24 Kurmi OP, Devereux GS, Smith WC, et al. Reduced lung function due to biomass smoke exposure in young adults in rural Nepal. Eur Respir J 2013; 41: 25-30.

25 Semple S, Devakumar D, Fullerton DG, et al. Airborne endotoxin concentrations in homes burning biomass fuel. Environ Health Perspect 2010; 118: 988-991.

26 Landrigan PJ, Fuller R, Acosta NJR, et al. The Lancet Commission on pollution and health. Lancet 2017; in press [https://doi.org/10.1016/S0140-6736(17)32345-0].

27 Burney P. Chronic respiratory disease - the acceptable epidemic? Clin Med (Lond) 2017; 17: 29-32. 